Article

\title{
North Africa and Saudi Arabia Day/Night Sandstorm Survey (NASCube)
}

\author{
Louis Gonzalez $^{1 \text {,* } \text { and Xavier Briottet }}{ }^{2}$ \\ 1 CNRS, UMR 8518-LOA-Laboratoire d'Optique Atmosphérique, University Lille, F-59000 Lille, France \\ 2 ONERA, The French Aerospace Lab, 2 Avenue Edouard Belin, 31055 Toulouse, France; \\ Xavier.Briottet@onera.fr \\ * Correspondence: Louis.Gonzalez@univ-lille1.fr
}

Received: 7 July 2017; Accepted: 25 August 2017; Published: 30 August 2017

\begin{abstract}
The Meteosat Second Generation (MSG) geostationary platform equipped with the Spinning Enhanced Visible and Infrared Imager (SEVIRI) instrument provides observations of the Earth every 15 min since 2004. Based on those measurements, we present a new method called North African Sandstorm Survey (NASCube) to: (i) generate day/night remote sensing images in order to detect sandstorms over the Sahara and Saudi Arabia; and (ii) estimate day and night aerosol optical depth (AOD). This paper presents a method to create true color day and night images from the SEVIRI instrument level 1.5 products and the complete operational data processing system to detect sandstorms and quantify the AOD over the desert areas of North Africa and Saudi Arabia. The designed retrieval algorithms are essentially based on the use of artificial neural networks (ANN), which seems to be well suited to this issue. Our methods are validated against two different datasets, namely the Deep Blue NASA moderate-resolution imaging spectroradiometer (MODIS) product and AErosol RObotic NETwork (AERONET) acquisitions located in desert areas. It is shown that NASCube products deliver better estimations for high AOD $(>0.2)$ over land areas than Deep Blue products. The open-public web platform will help researchers to identify, quantify and retrieve the impact of sandstorms over desert regions.
\end{abstract}

Keywords: SEVIRI; sandstorm; day and night AOD retrieval; North Africa; Saudi Arabia

\section{Introduction}

Aerosols have an impact on the total radiative forcing [1] by scattering the shortwave solar radiation, absorbing long wave terrestrial radiation [2] and also by modifying indirectly cloud properties [3-6].

Mineral dust is one of the major aerosol types affecting our environment as it has one of the deepest boundary layers on the planet during the summer months [7]. More particularly, the Sahara is the largest source of mineral dust aerosols in the world (e.g., [8]). Slingo et al. [9] have estimated the increase of the reflected shortwave radiation during a dust storm event by as much as $100 \mathrm{~W} \cdot \mathrm{m}^{-2}$. Each year, about 400 to 700 million tons of dust particles are transported from the Sahara and about 40 million tons are deposited on the Amazon River basin [10]. Such dust storms also have a key impact on the ecosystems and their functioning (See [11] and references therein). Mineral dust is mainly composed of ferric oxides, which absorb at the short wavelengths [12,13], and phosphorous [14]. The aerosols impact can be seen on ecosystems even distant from the source regions, by providing nutrients for oceanic microorganisms $[15,16]$ or by fertilizing the Amazon rainforest $[17,18]$. Furthermore, dust particles impact the air quality. In Spain, Escudero et al. [19] have shown that the dust contribution of particulate matter $\left(\mathrm{PM}_{10}\right)$ ranges from $44 \%$ to $100 \%$ in summer, when exceeding the daily limit value of $50 \mu \mathrm{m} / \mathrm{m}^{3}$ (1993/30/CE European directive). Gobbi et al. [20] drew similar conclusions (63-68\%) over Roma. 
In this contact, there is a real need to monitor sandstorms with a very high temporal revisit time. The AErosol RObotic NETwork (AERONET) network (see the references on the AERONET webpage [21]) provides aerosol optical depth (AOD) estimations with a very good accuracy for hundreds of measures during the day. Unfortunately, the limited number of geographical areas for AERONET stations does not allow the monitoring of sandstorms at a global scale. On the contrary, remote sensing is a powerful tool to derive dust information such as the identification of dust source regions [22,23], their distribution and intensity (e.g., [24,25]), and the mechanisms associated with dust emission (e.g., [8,26]). Products such as the Deep Blue moderate-resolution imaging spectroradiometer (MODIS) data [27] (see also Deep Blue NASA website [28]) give access to a global monitoring of sandstorm events, over bright desert surfaces, but the reduced number of observations, almost two per day for MODIS remains a strong drawback. The high temporal resolution sensor Spinning Enhanced Visible and Infrared Imager (SEVIRI) has opened the way to map sub daily scale variability of dust presence [24,29,30]. The methods based on structure functions [31] make possible the detection of dust events by using the Infrared Difference Dust Index (IDDI) but do not allow retrieving the corresponding AOD. An alternative solution was proposed by Klüser et al. [32], and Schepanski et al. [24,29] who suggested to use the high acquisition frequency of a geostationary instrument, Meteosat Second Generation (MSG-SEVIRI), to map the detection of aerosols with a strong sub-daily revisit time. However, the reproducibility of these results is constrained not only by the fact that the interpretation of the dust signal in the images is subjective, but also because the analysis is very computer-time intensive. Therefore, Ashpole et al. [30], proposed a method to automate the detection process from SEVIRI but on a reduced basis of a single case study in June 2010. However, their short-time study bypasses the real difficulties of the sandstorm detection method, as it does not take into account the extreme seasonal day/night variabilities of the input measurements, which makes it precisely very difficult to define any aerosol detection threshold. Other recent attempts [33-35] to detect mineral dust from the MSG-SEVIRI measurements, perform with reasonable success in daytime for specific events, but do not link the detection to AOD values. Brindley et al. [36] and Romano et al. [37] were among the few to estimate dust AOD values from a look-up-table, and to apply it to a reduced number of datasets. None of the published methods offers a detection in nighttime.

All these arguments motivate the development of a new dust detection methodology, NASCube (North African Sand Storm Survey), with the aim of providing a sandstorm detection that is fully general, working both day and night and valid for any season of the year. Moreover, for the sake of distributing the analyzed images acquired by the MSG2-SEVIRI geostationary instrument, a new visible real color and thermal images are delivered to differentiate at the first glance the main classes of objects, such as clouds, surfaces, or dusts, composing the images. NASCube provides a $24 \mathrm{~h}$ detection and characterization of sandstorms to track their evolution over North Africa and Saudi Arabia. This project was originally supported by the African Monsoon Multidisciplinary Analysis (AMMA) experience [38] and funded by the French institutes Institut Pierre-Simon Laplace (IPSL)/Centre National de la Recherche Scientifique (CNRS)-Université Pierre and Marie Curie (UPMC)-Université Versailles Saint Quentin (UVSQ), Cloud-Aerosol Lidar and Infrared Pathfinder Satellite Observation (CALIPSO) co-PI. The first results have been used in several experiments, as demonstrated by the website citations in the papers $[7,39,40]$.

In 2011, the FENNEC project (The Saharan Climate System) gave us an opportunity to upgrade the platform, under the new name NASCube, with several objectives: (1) improve the detection of sandstorms; (2) retrieve the day/night AOD from sandstorms values; (3) improve the standalone system that computes and distributes the results in real time.

This paper presents the methodology to create true color visible images from the SEVIRI instrument level 1.5 product in Section 2.1 and the complete operational data processing system to detect and quantify the sandstorms in Section 2.2. The retrieval algorithms are based on the use of artificial neural networks (ANN). Section 3 compares the AOD NASCube retrievals with the Deep Blue NASA MODIS results and with the AERONET [21,41] AOD in-situ measurements. 


\section{Methodology}

The NASCube system processes METEOSAT (MSG2) SEVIRI instrument level 1.5 data from EUMETSAT, expressed in radiance units $\left(\mathrm{W} \cdot \mathrm{sr}^{-1} \cdot \mathrm{m}^{-2}\right)$ in only eight of the twelve bands, referenced by their central wavelength: $0.6,0.8,1.6,3.9,8.7,9.7,10.8$, and $12.0 \mu \mathrm{m}$ (Figure 1).

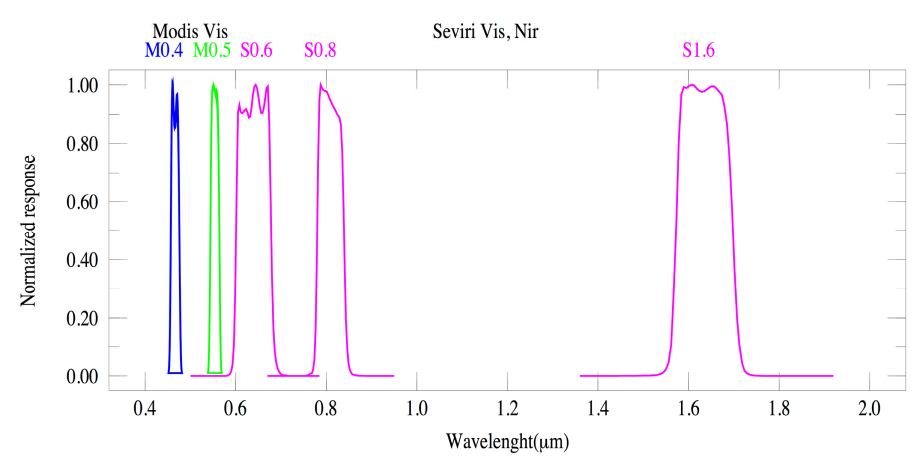

Figure 1. Spectral bands of SEVIRI. The data are acquired in real-time every $15 \mathrm{~min}$ from the EUMETSAT satellite and are processed by the EUMETSAT ground processing to deliver the LEVEL1 end products.

The flowchart displayed in Figure 2 is useful to guide the reader through the various stages of the NASCube algorithm. The first step (Section 2.1) aims at generating in daytime (Section 2.1.1) a synthetic image close to real visible color composite image. Further, in nighttime (Section 2.1.2), a pseudo color composite image is built from several infrared and thermal bands. The second step (Section 2.2) is devoted to the estimation of the AOD during the day and at night. To this end, a cloud mask is first developed, followed by the detection of the aerosol event with an estimate of its AOD.

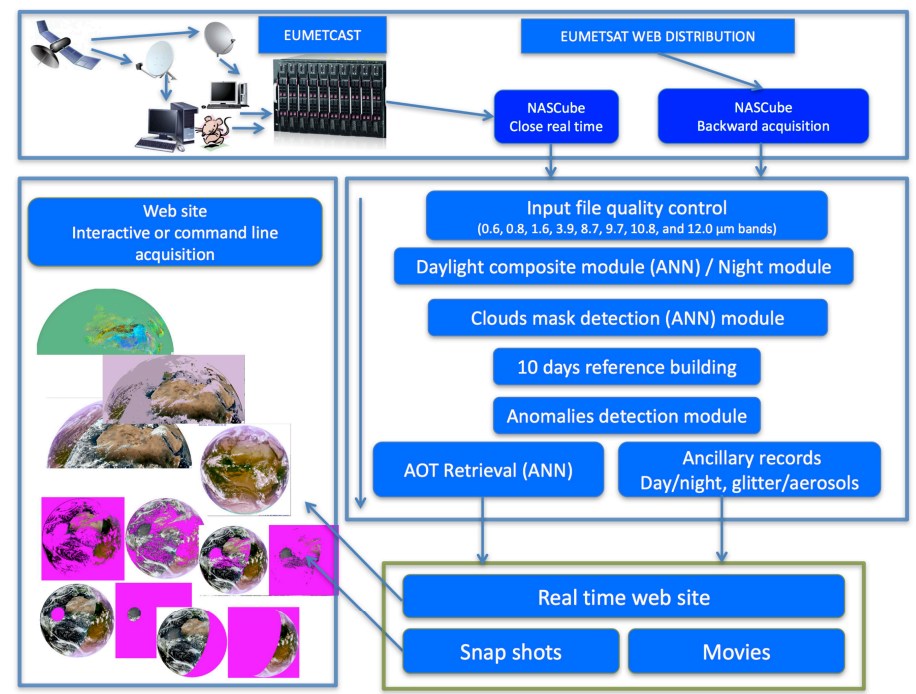

Figure 2. NASCube flowchart. NASCube system is divided in three levels: The first level is devoted to the data acquisition and is divided in two segments, one receiving the close near real time data using an antenna for the EUMETCast distribution and the other processing the EUMETSAT archive query system to go backward in time (one year of results needs to process 4.5 terabytes of data). The second level computes the different masks of clouds and glitters, creates the color composite images and computes the AOD fields. Some steps use artificial neural networks (ANN). The third one creates all the subsets needed by the web distribution and the user specific tasks. 


\subsection{Generation of a SEVIRI Image in Pseudo Color}

\subsubsection{Daytime SEVIRI Image}

Traditional SEVIRI images are in artificial colors due to the lack of the blue and green visible bands [42]. We hereafter describe our methodology, which relies on the use of an ANN to synthetize the missing bands $(0.4$ and $0.5 \mu \mathrm{m})$ in daytime.

In the first step, the discrimination between night and day is achieved by selecting images acquired with a solar zenith angle $\left(<84.0^{\circ}\right.$ for daytime pixels) empirically determined by the quality of the rendered RGB visible images.

To obtain natural colors in the visible bands, the minimum atmospheric correction required is the compensation for the Rayleigh scattering contribution, to which a correction for ozone aerosols was added according to the $6 \mathrm{~S}$ radiative transfer code [43]. Let $\mathrm{L}_{\mathrm{m}}\left(\mathrm{W} \cdot \mathrm{sr}^{-1} \cdot \mathrm{m}^{-2}\right)$ be the SEVIRI Top Of Atmosphere (TOA) radiance in band $\mathrm{m}$ and $\rho_{\mathrm{m}}$ the TOA reflectance, calculated as:

$$
\rho_{\mathrm{m}}=\pi \mathrm{L}_{\mathrm{m}} / \mu_{\mathrm{s}} \mathrm{E}_{\mathrm{s}}
$$

with $\mu_{\mathrm{s}}=\cos \theta_{\mathrm{s}}$, where $\theta_{\mathrm{s}}$ is the solar zenith angle, and $\mathrm{E}_{\mathrm{s}}$ is the solar flux at the top of the atmosphere. The Rayleigh and ozone corrections assuming a Lambert's law of the surface reflectance defines $\rho_{\mathrm{m}, \mathrm{c}}$ as:

$$
\rho_{\mathrm{m}}=\mathrm{T}_{\mathrm{O}_{3}}\left[\rho_{\mathrm{atm}}+\frac{\mathrm{T}\left(\mu_{\mathrm{s}}\right) \mathrm{T}\left(\mu_{\mathrm{v}}\right) \rho_{\mathrm{s}}}{1-\rho_{\mathrm{s}} \cdot \mathrm{S}_{\mathrm{alb}}}\right]
$$

where $\rho_{\mathrm{S}}$ stands for the surface reflectance and $\mu_{\mathrm{v}}=\cos \theta_{\mathrm{v}}$, with $\theta_{\mathrm{v}}$ the view zenith angle as defined in the $6 \mathrm{~S}$ reference manual $[43,44]$. In Equation (2), $\mathrm{T}_{\mathrm{O}_{3}}$ accounts for the light absorption on the direct downward and upward paths through the stratospheric ozone layer, mainly above the molecular atmosphere:

$$
\mathrm{T}_{\mathrm{O}_{3}}=\exp \left(-\mathrm{A}_{\mathrm{O}_{3}} \cdot \mu_{\mathrm{O}_{3}} \cdot\left(\frac{1}{\cos \theta_{\mathrm{S}}}+\frac{1}{\cos \theta_{\mathrm{v}}}\right)\right),
$$

where $\mu_{\mathrm{O}_{3}}$ is the ozone absorber amount for each satellite wavelength, and $\mathrm{A}_{\mathrm{O}_{3}}$ is the ozone absorption coefficient by Shettle et al. [45], tabulated in steps of $200 \mathrm{~cm}^{-1}$ between 13,000 and $24,200 \mathrm{~cm}^{-1}$ and by steps of $500 \mathrm{~cm}^{-1}$ between 27,500 and $50,000 \mathrm{~cm}^{-1}$.

The other terms of Equation (2) correspond to atmospheric effects and are estimated assuming both a black surface and a pure molecular atmosphere. $\rho_{\mathrm{atm}}$ is the atmospheric reflectance that corresponds to the light directly scattered by the atmosphere. It is computed by the analytical expressions [46] that reproduce Chandrasekhar isotropic scattering values [47]. $\mathrm{T}\left(\mu_{\mathrm{s}}\right)$ and $\mathrm{T}\left(\mu_{\mathrm{v}}\right)$ are the transmission fluxes of the atmosphere on the path between the sun and the surface, and, respectively, between the surface and the sensor. Both are estimated from the Delta-Eddington approximation [48], such as

$$
\mathrm{T}(\mu)=\frac{(2 / 3+\mu)+(2 / 3-\mu) \cdot \mathrm{e}^{-\tau / \mu}}{(4 / 3+\tau)}
$$

where $\mu$ is the cosine of the solar and/or observational zenith angle and $\tau$ is the optical thickness. $S_{a l b}$ is the spherical albedo of the atmosphere. For a pure molecular atmosphere and for some observation conditions $\left(\mu_{\mathrm{s}}, \mu_{\mathrm{v}}\right.$ and $\left.\rho_{\mathrm{S}}\right)$, numerical figures of $\rho_{\mathrm{m}}$ were derived directly (independently) from the "successive orders of scattering" code of Lenoble and al. [49]. By reporting these contributions to the left-hand side of Equation (2), $S_{\text {alb }}$ can be derived, leading to $S_{a l b}=0.0497,0.0198$, and 0.0012 for wavelengths $0.615,0.810$ and $1.64 \mu \mathrm{m}$, respectively. Assuming that $\rho_{\mathrm{s}} \cdot \mathrm{S}_{\mathrm{alb}}\left(\rho_{\mathrm{s}} \cdot \mathrm{S}_{\mathrm{alb}}\right) \ll 1$ in Equation (2), the surface reflectance can be computed as:

$$
\rho_{\mathrm{s}}^{*}=\frac{\left(\rho_{\mathrm{m}} / \mathrm{T}_{\mathrm{O}_{3}}-\rho_{\mathrm{atm}}\right)}{\mathrm{T}\left(\mu_{\mathrm{s}}\right) \mathrm{T}\left(\mu_{\mathrm{v}}\right)} .
$$


from which, the surface reflectance is computed as

$$
\rho_{\mathrm{s}}=\frac{\rho_{\mathrm{s}}^{*}}{1+\mathrm{S}_{\mathrm{alb}} \cdot \rho_{\mathrm{s}}^{*}}
$$

Finally, the synthetic bands at 0.4 and $0.5 \mu \mathrm{m}$ are generated with an ANN. The structure of the ANN (input, layers, and outputs) was determined empirically using the Stuttgart Neural Network Simulator (SNNS) [50], until reasonable visible RGB composite images $(0.4,0.5,0.6 \mu \mathrm{m})$ could be obtained. Thus, the working ANN uses four inputs (three reflectances in bands $0.6,0.8$, and $1.6 \mu \mathrm{m}$, and the $\frac{\rho_{0.6, c}}{\rho_{0.8, c}}$ ratio) and two hidden layers with 10 nodes each, and yields two outputs, the reflectances ratios $\frac{\rho_{0.6, c}}{\rho_{0.4, c}}$ and $\frac{\rho_{0.6, c}}{\rho_{0.5, c}}$, used to retrieve the 0.4 and $0.5 \mu \mathrm{m}$ reflectance values.

As shown in Figure 1, SEVIRI and MODIS have similar spectral bands at 0.6, 0.8 and $1.6 \mu \mathrm{m}$. This spectral overlap is used to train the ANN with MODIS level1B measured reflectances over several surfaces (ocean, desert, clouds, green regions) with the same Rayleigh and ozone corrections. Although these spectral bands are not exactly the same between SEVIRI and MODIS, the spectral behavior of the considered landscapes evolves slowly. This allows us to assimilate the MODIS data products to generate the SEVIRI ones.

Once the $0.4 \mu \mathrm{m}$ and $0.5 \mu \mathrm{m}$ synthetic reflectances are estimated, the final Pseudo Visible natural-color Composite (PVC) can be built by log-transforming the 0.4, 0.5, and $0.6 \mu \mathrm{m}$ output reflectances to 8 bits [0; 255] RGB visible bands (PVC) colors:

$$
\operatorname{PVC}\left(\lambda_{m}\right)=256 \times \frac{\log \left(10,000 \times \rho_{m, c}\right)-\min }{(\max -\min )},
$$

with $\min =5.8 ; \max =9.4$ for all three bands. These coefficients were empirically determined from a few image histograms to obtain good contrasted images.

\subsubsection{Night SEVIRI Image}

In nighttime, an empirical algorithm was developed with the primary aim to keep a visual day/night white color transition of the clouds. The final night composite is sufficiently sensitive to show in the video animations the propagation of the thermal changes over the surface. Three SEVIRI bands 3.9, 8.7, and $9.7 \mu \mathrm{m}$ radiances are used to build the RGB Pseudo Night Composites (PNC) for each instrument acquisition. The final image is directly computed using a linear-log transformation of the corresponding radiance values:

$$
\operatorname{PNC}\left(\lambda_{i}\right)=256 \times \frac{\log \left(10,000 \times\left(a_{i}-b_{i} \rho_{i}\right)\right)-\min _{i}}{\left(\max _{i}-\min _{i}\right)},
$$

with the parameters listed in Table 1, which were empirically adjusted to yield the best contrast for the resulting night images, as illustrated in Figure 3.

Table 1. Parameters for the linear-log transformation to the Pseudo Night Composites.

\begin{tabular}{cccccc}
\hline Band $\left(\boldsymbol{\lambda}_{\boldsymbol{i}}\right)$ & PNC Channel & $\boldsymbol{a}_{\boldsymbol{i}}$ & $\boldsymbol{b}_{\boldsymbol{i}}$ & $\boldsymbol{m i n}_{\boldsymbol{i}}$ & $\boldsymbol{m a x}_{\boldsymbol{i}}$ \\
\hline $3.9 \mu \mathrm{m}$ & $\mathrm{R}$ & 0.004478 & 1.308425 & 7.5 & 9.5 \\
$8.7 \mu \mathrm{m}$ & $\mathrm{G}$ & 0.001732 & 1.247040 & 7.7 & 9.5 \\
$9.7 \mu \mathrm{m}$ & $\mathrm{B}$ & 0.003362 & 1.899304 & 7.5 & 9.5 \\
\hline
\end{tabular}




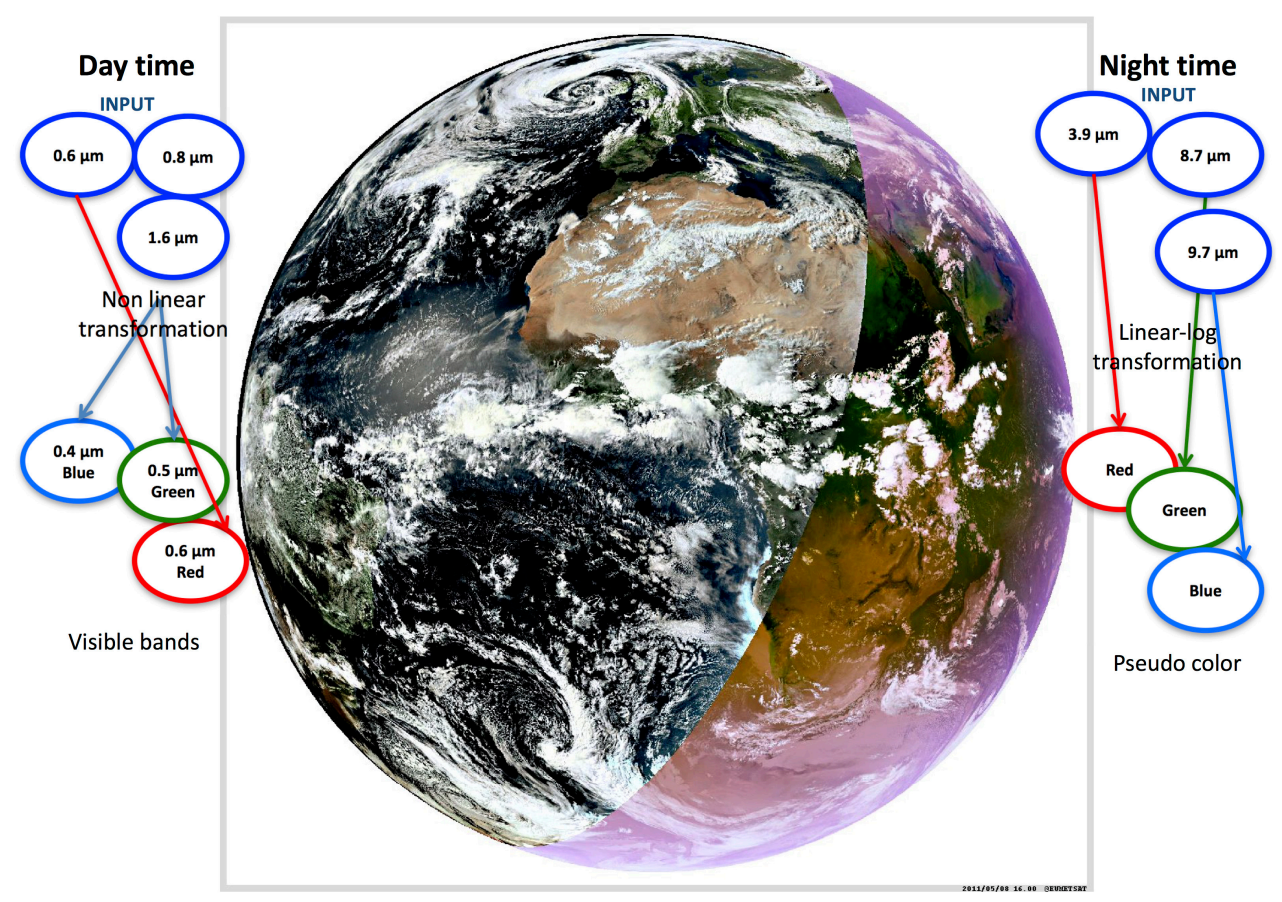

Figure 3. Day/night color rendering illustration. The RGB color composites are built from the input data (upper blue circles) by non-linear ANN (day-time) and linear-log transformation (nighttime).

\subsection{Aerosols Detection and AOD Estimation}

\subsubsection{Introduction}

The designed AOD retrieval algorithm follows three steps bypassing the use of specific selection thresholds to detect sandstorms.

In the first step, we create a sandstorm color anomaly using the well-known dust RGB EUMETSAT composite [51,52] based on three infrared bands, 8.7, 10.8, and $12.0 \mu \mathrm{m}$. This has proven to be very helpful in dust storms detections over desert areas, because mineral dust aerosols have a high variable transmission and emission between 8 and $12 \mu \mathrm{m}$ [53]. However, this sole RGB product is not sufficient to discriminate sandstorms from clouds or background thermal anomalies. To accurately detect sandstorms, we had, in a second step, to devise not only a reliable cloud mask but also a mean value background (a 10-day rolling average) as detailed further below. It is noteworthy that a preliminary version of this step was implemented in 2006/2007 in the first AMMA database.

In the third step, we train an ANN to correlate the DUST 3 bands fluctuations with several years of AERONET measurements over 10 specific areas to compute AOD values.

\subsubsection{Thermal Anomaly Detection}

The dust RGB EUMESAT dust composite uses the three Pseudo Thermal Bands (PTB) defined as:

$$
\begin{gathered}
\mathrm{PTB}_{1}=\mathrm{T}_{\mathrm{B}}(12.0 \mu \mathrm{m})-\mathrm{T}_{\mathrm{B}}(10.8 \mu \mathrm{m}) \\
\mathrm{PTB}_{2}=\mathrm{T}_{\mathrm{B}}(10.8 \mu \mathrm{m})-\mathrm{T}_{\mathrm{B}}(8.7 \mu \mathrm{m}) \\
\mathrm{PTB}_{3}=\mathrm{T}_{\mathrm{B}}(10.8 \mu \mathrm{m})
\end{gathered}
$$

Unfortunately, this product gives us a qualitative color contrast that encompasses all thermal anomalies including clouds, land and sandstorm. Thus, an improved algorithm to discriminate clouds from sand storms is proposed in two steps. 
The first step aims at delivering finer cloud detection. Indeed, as illustrated in Figure 4, it can be clearly noted that the METEOSAT cloud Mask (CLM) [54] has notable limitations, such as erroneous cloud detection, assignment of sandstorms as clouds and failure in detecting clouds over dark land. This motivated the design of a new cloud mask using machine-learning techniques based on ANN algorithms. Unlike the ANN recently proposed by Taravat et al. [55], that only provides daytime cloud detection, our platform includes season-specific ANNs:

(a) Empirically, and after several trials and errors, it was chosen to divide the year into eight periods of approximately 40 days and to separate day and night cases over ocean (2) and land (2).

(b) As a result, a cloud of $40 \times 2 \times 2$ ANNs was computed. All ANNs take seven input data, and are built with two hidden layers with 10 nodes each, and lead to one cloudy flag output 0 or 1 .

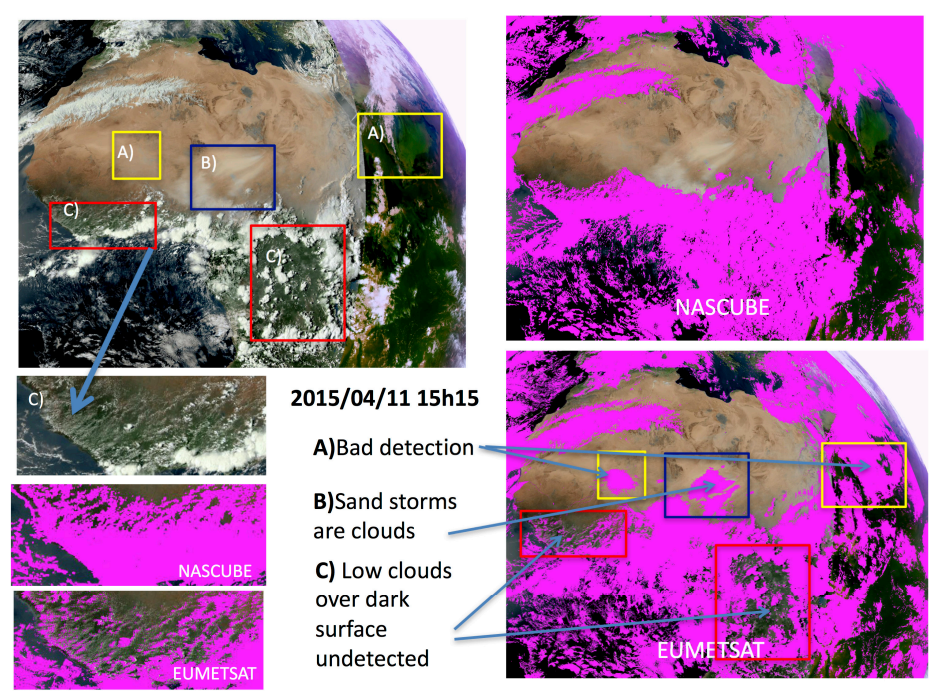

Figure 4. Comparison of NASCube EUMETSAT cloud mask products on the right hand side (highlighted in magenta) for one slot on 11 April 2015 at 15:15. On the left, several areas are drawn to highlight the deficiencies of the EUMETSAT cloud mask detection: (A) two areas (yellow rectangles) showing erroneous cloud detections; (B) one area (blue rectangle) showing that EUMETSAT assigns sandstorms as clouds; and (C) two areas (red rectangles) illustrating the failure of EUMETSAT cloud mask in detecting low clouds over dark surfaces.

For the daytime ANN, the seven inputs are the latitude, the three PVC bands, and the three PTB bands. For the nighttime ANN, the seven inputs are the latitude; the radiances at $3.9 \mu \mathrm{m}, 8.7 \mu \mathrm{m}$, and $9.7 \mu \mathrm{m}$; and the three PTB bands.

The ANNs were trained with an iterative empirical process, which involves the selection of several millions of pixels in representative cloudy areas to build the training set, then a subsequent visualization of the resulting cloud mask, and the correction of potential imperfections by growing the training input datasets with additional pixels.

Figure 4 demonstrates that our cloud mask corrects some discrepancies of the CLM EUMETSAT product and is able to accurately distinguish clouds from sandstorms.

Having built a reliable cloud mask, the second issue is to discriminate sandstorm events among the thermal anomalies. First, a rolling cloudfree average background of the PTB within a period of 10 days (REF_PTB) is computed as a reference for each of 96 time slots at the pixel level, using our new cloud mask. The choice of 10 days has been fixed empirically, as it seems to be the minimum number of days to have cloud-free values over the whole area.

$$
\text { REF_PTB } 1=<\mathrm{T}_{\mathrm{B}}(12.0 \mu \mathrm{m})-\mathrm{T}_{\mathrm{B}}(10.8 \mu \mathrm{m})>
$$




$$
\begin{gathered}
\text { REF_PTB }{ }_{2}=<\mathrm{T}_{\mathrm{B}}(10.8 \mu \mathrm{m})-\mathrm{T}_{\mathrm{B}}(8.7 \mu \mathrm{m})> \\
\text { REF_PTB }_{3}=<\mathrm{T}_{\mathrm{B}}(10.8 \mu \mathrm{m})>
\end{gathered}
$$

where $<>$ stands for the average of the REF_PTB $i$ over the free clouds data among the 10 days, every $15 \mathrm{~min}$ and the three channels $i=1,2,3$.

The atmospheric anomalies (sandstorm and clouds) are revealed by the following difference contrast $\mathrm{SAA}_{\mathrm{i}}=\mathrm{PTB}_{\mathrm{i}}-\mathrm{REF} \mathrm{PTB}_{\mathrm{i}}$ in $\mathrm{W} \cdot \mathrm{sr}^{-1} \cdot \mathrm{m}^{-2}$. Finally, the sandstorm is detected by filtering the remaining data which are not cloudy again using our new cloud mask delivering our new sandstorm detection layer named hereafter SAA (SAnd Anomaly).

\subsubsection{SAA Examples}

To illustrate magnitude and evolution of SAA values, Figure 5 displays the SAA composite in the Sahara region for three days, 6, 8, and 9 January 2011: 6 January is free of anomalies, 8 January exhibits a huge sandstorm during the day and 9 January contains a sandstorm during the night. Figure 5 also shows the three components of the SAA across two specific transects during daytime and nighttime. Among the three SAA channels, the green $(10.8-8.7 \mu \mathrm{m})$ and blue $(10.8 \mu \mathrm{m})$ pseudo bands are the ones that fluctuate the most in the presence of a sandstorm, noting that the sign of the deviations for the blue band changes from daytime to nighttime as a result of the night thermal inversion. This demonstrates that SAA values can be used to detect sandstorm anomalies.

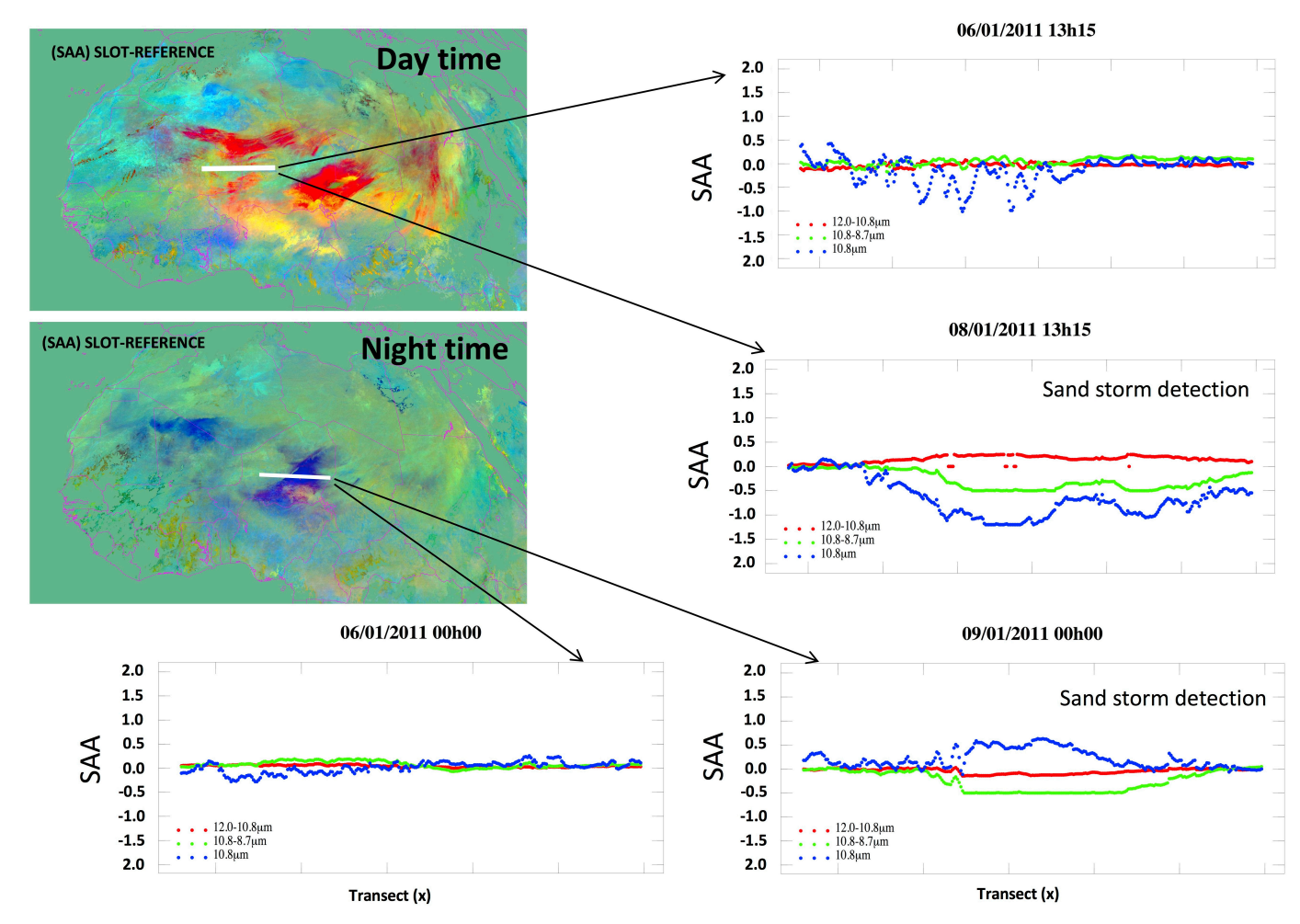

Figure 5. Plots of SAA values in $\mathrm{Ww} \cdot \mathrm{sr}^{-1} \cdot \mathrm{m}^{-2}$ (in red, 12.0-10.8 $\mu \mathrm{m}$, in green 10.8-8.7 $\mu \mathrm{m}$, and in blue $10.8 \mu \mathrm{m}$ ) across spatial transects in the Sahara area (marked as bold white lines) for a sandstorm free day (6 January 2011) and stormy days (8 January 2011) in daytime and (9 January 2011) in nighttime.

\subsubsection{Validation of the Pseudo-Color Construction and NASCube Sandstorm Detection}

To qualitatively validate the pseudo-color construction and the sandstorm detection, we present in Figure 6 a comparison of the results with two time synchronized MODIS granules acquisition on 19 February 2011, illustrating the fidelity of the detection on land of a sandstorm over Egypt and the Mediterranean Sea. Note that the anomaly detection algorithm has only been implemented over bright 
land so far and is thus not able to capture the sandstorms visible neither over the green Nile Delta nor over Sea.

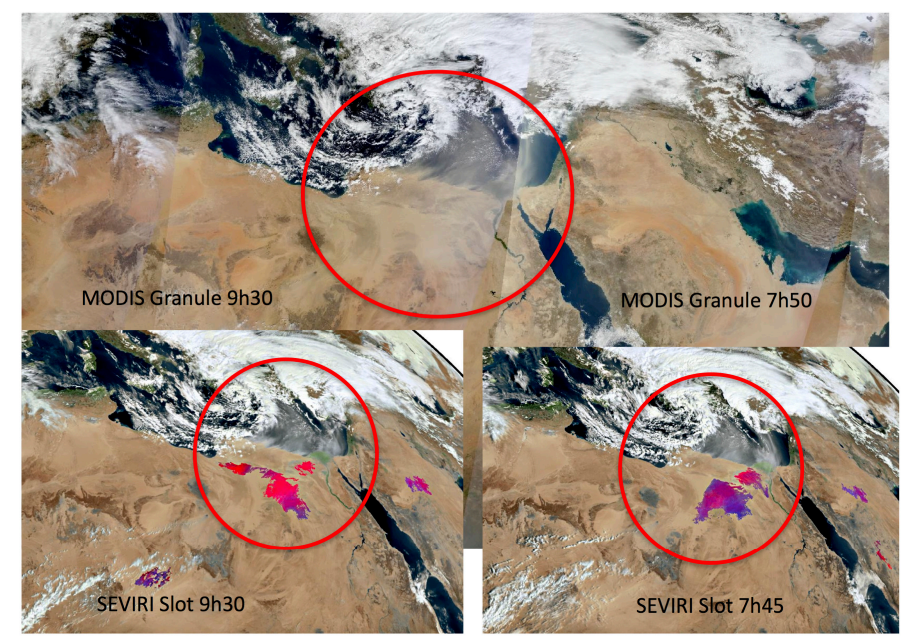

Figure 6. MODIS (Plate Carre projection) (top) versus SEVIRI (No projection) (bottom) (19 February 2011).

\subsubsection{AOD Retrieval Method}

Our ultimate goal is to retrieve AOD in an operational process by establishing a correlation between the pseudo-color anomalies SAA and AOD values. For that purpose, we have used AERONET AOD measurements [41] for several wavelengths (1.640, 1.020, 0.870, 0.675, 0.500, 0.440, 0.380, and $0.340 \mu \mathrm{m}$ ), from 10 sites geolocalized in Figure 7 (Dakar, Banizoumbou, Tamanrasset, Solar_Village, Malaga, El Arenosillo, Agoufo, Saada, Sede_Boker, and IER_Cinzana) over six-years from 2007 to 2012.

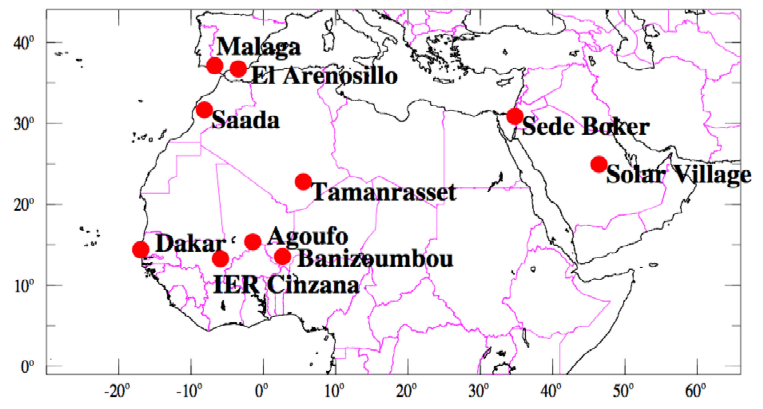

Figure 7. Localization map of the 10 AERONET sites used in the AOD training.

The first point was to verify whether there is a correlation between the AERONET AOD measurements and the color patterns in the SAA product. In this context, a binary mask (yes/no) is built from the difference of the 12.0 and $10.8 \mu \mathrm{m}$ thermal bands. A threshold value of $0.16 \mathrm{~W} \cdot \mathrm{sr}^{-1} \cdot \mathrm{m}^{-2}$ is chosen to select the stronger colored events of SAA over the AERONET sites. Figure 8 shows the time and spatial coincidences between AERONET AOD values and the NASCube sandstorm binary masks (replaced in the figure by the original SAA RGB values), over Tamanrasset from June to August 2007 and over El-Arenosillo from July to December 2007, when the sandstorm crosses the Mediterranean Sea. When a sandstorm is detected a blue circle is drawn using as coordinates $\mathrm{X}$ the time and $\mathrm{Y}$ the corresponding AOD found by AERONET.

Figure 8 clearly shows a series of measurements associated to the SAA color outputs. It appears that the SAA values computed at the exact AERONET time (bottom series of snapshots) match the highest atmospheric optical thickness values measured by AERONET, except when clouds interfere. 
In these cases, the upper snapshots show the first available NASCube snapshot with a high AOD value within a time window not exceeding two hours.

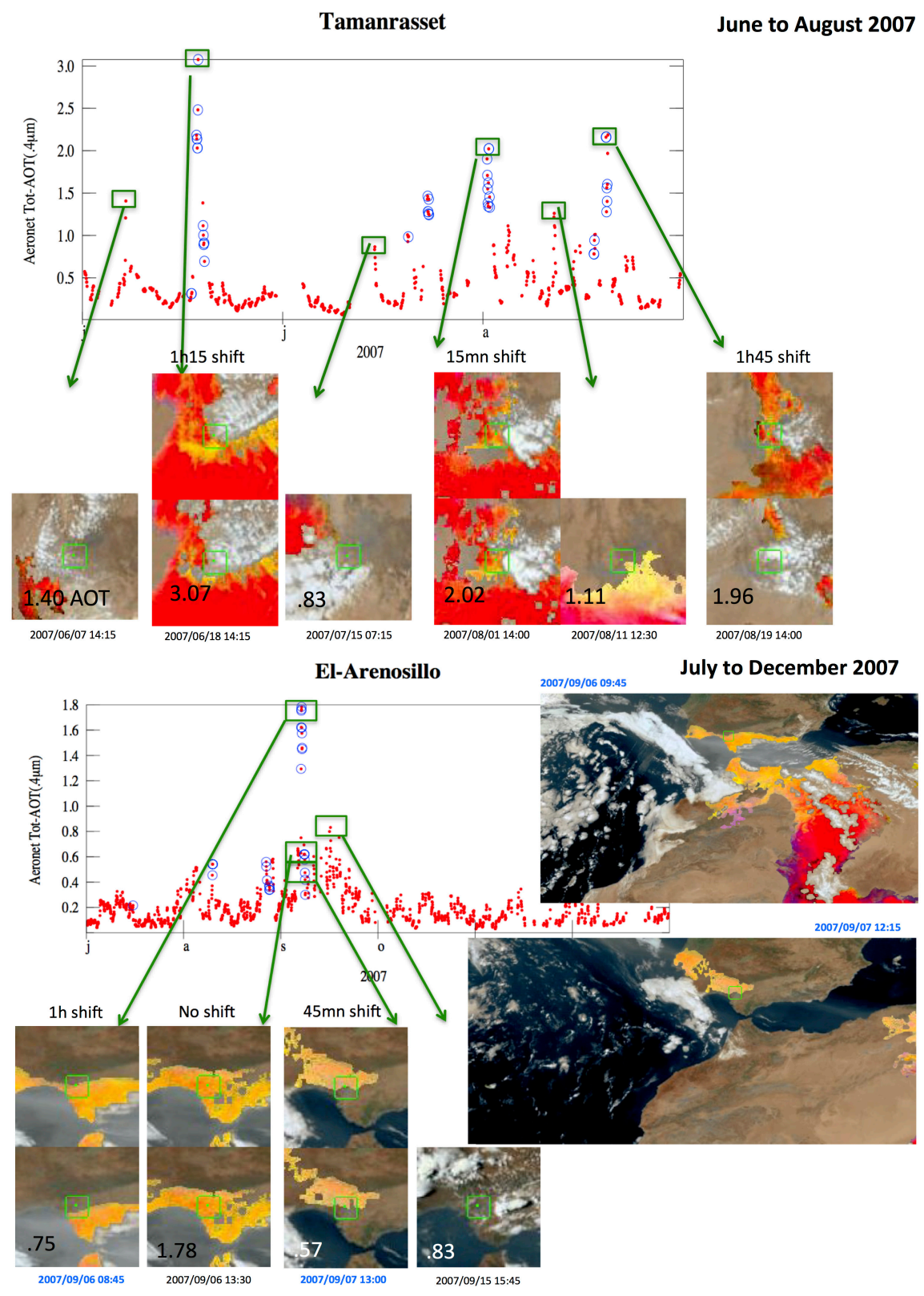

Figure 8. Temporal evolutions of AERONET measurements (red dots) for two sites (top: Tamanrasset; and bottom: El-Arenosillo). A blue circle is drawn when the NASCube sandstorm mask (in the figure the mask is replaced by the SAA RGB values) detects a stormy point that time-wise and spatial-wise coincides with AERONET AOD values. Some high AOD events are detected by NASCube with a time delay not exceeding two hours.

As shown in Figure 9 there is a clear correlation between the AOD measured with AERONET and our SAA product. Thus, this correlation is further modeled using an ANN tool. After many tests, it appeared that the best AERONET correlation was obtained using an ANN with 10 inputs (three PTB, three REF_PTB, three SAA, and the AERONET wavelength), two hidden layers with eight nodes each and as output the AERONET measurement. Figure 9 displays a comparison of the AOD values predicted by the ANN with the AERONET measurements taken from 2007-2012. The good agreement across a large number of measurements (from about 10,000 to 150,000) demonstrates the quality of the 
designed AOD SEVIRI retrieval model across all wavelengths. Its validation will be further illustrated in Section 3.
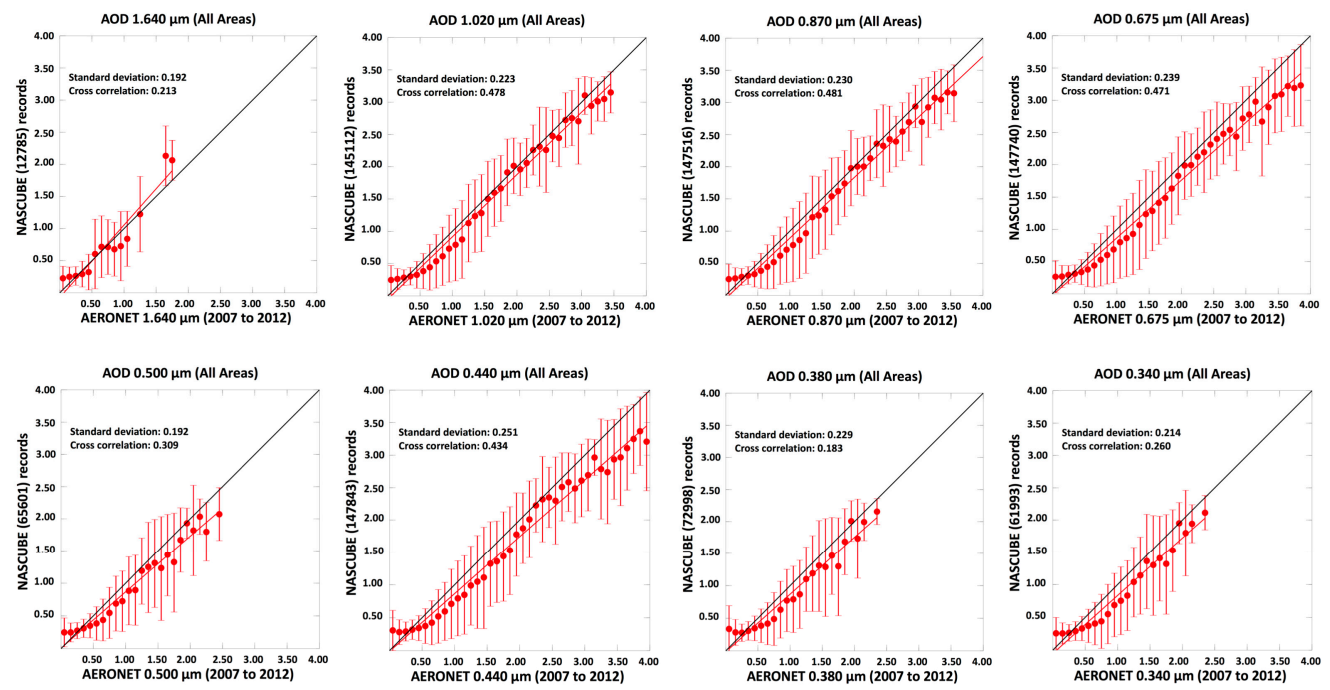

Figure 9. Operational neural AOD retrieval model. The mean (dots) and standard deviation of the NASCube AOD retrievals versus the input AERONET measurements for AOD value split in classes of 0.1 for all wavelengths, for values covering 2007 to 2012.

\subsubsection{Validation of AOD Retrieval Method}

To fully demonstrate that the AOD retrieval performs well, we select the AERONET AOD values from the available sites in 2016 (Dakar, Malaga, El Arenosillo, Saada, Sede_Boker, IER_Cinzana). As we have already shown, the synchronization between the AERONET and SEVIRI measurements is not perfect, especially near cloudy areas, introducing a slight bias when comparing NASCube to AERONET data. However, the comparison presented in Figure 10 for year 2016 comforts us in the quality of the AOD NASCube model, as the results are of similar quality to that used in the training dataset (see Figure 9).

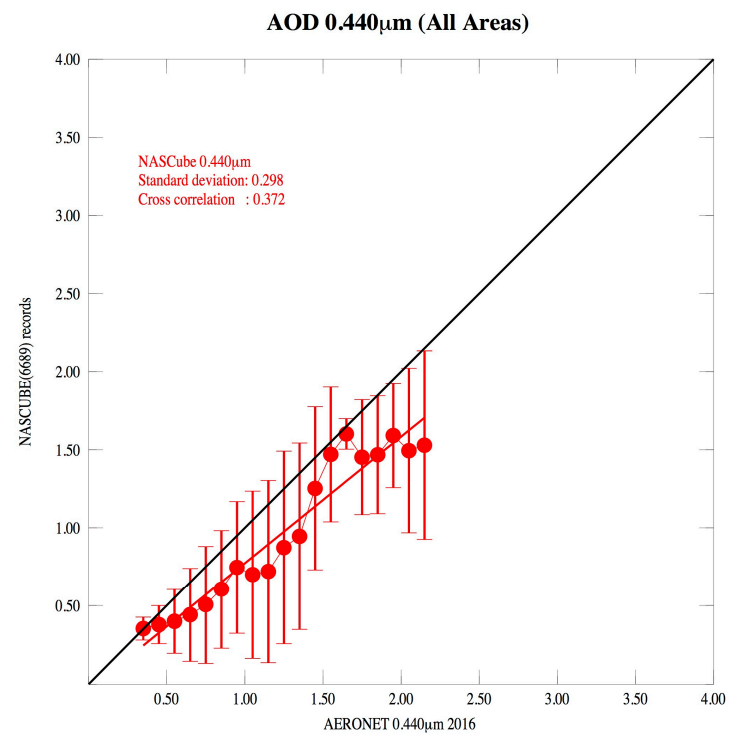

Figure 10. Comparison of AOD values obtained with NASCube retrieval model to AERONET ones for year 2016 at a wavelength of $0.44 \mu \mathrm{m}$. Mean (dots) and standard deviations are computed for AERONET AOD value classes of 0.1, excluding AOD values below 0.3 . 


\section{Results and Discussion}

\subsection{Data Description}

There are two types of instruments that provide AOD values; the in-situ instruments as those implemented by the AERONET network with, a very good accuracy and hundreds of measurements per day and the satellites retrievals as Deep Blue using the MODIS experiment with large scenes. The limitations that we are facing are the limited number of geographical areas for AERONET and the reduced number of images, up to two per day for MODIS. The geostationary MSG-SEVIRI instrument provides an extraordinary tool with a global vision of the North African and Saudi Arabia deserts and images every $15 \mathrm{~min}$, which allow following the evolution and trajectories of the sandstorms.

\subsection{Selection of Data For The Comparison of AOD Values (NASCube, AERONET, Deep Blue)}

The NASCube AOD retrieved values are validated against AERONET and Deep Blue AOD values. This implies:

(1) Selecting over six years, from 2007 to 2012, of AERONET AOD measurements for several wavelengths $(0.675,0.500,0.440 \mu \mathrm{m})$, from 10 sites geolocalized in Figure 7.

(2) Over the same time period, we extract the corresponding pixel over land from the Deep Blue MYD04L2 NASA PRODUCT the AOD at $0.550 \mu \mathrm{m}$.

(3) Time and space ( \pm 1 pixel around the AERONET site) synchronized NASCube retrievals $(0.675$, $0.500,0.440 \mu \mathrm{m})$.

\subsection{Validation of AOD Retrievals with Respect to AERONET and Deep Blue in Daytime}

This validation is achieved in two steps. Firstly, data acquired during daytime are validated by comparing the results between the three instruments simultaneously for the six years (2007-2012). To this end, we synchronize the locations and acquisition time of all measurements to compute the standard deviations for different locations and period of integration time assuming that the AERONET measurements are the reference. In order to have a maximum number of measurements we use the wavelengths available for AERONET site: Deep Blue at $0.550 \mu \mathrm{m}$, AERONET and NASCube 0.440 $\mu \mathrm{m}, 0.500 \mu \mathrm{m}$ and at Dakar $0.675 \mu \mathrm{m}$. Note that AOD values vary smoothly through the $0.4-0.6 \mu \mathrm{m}$ spectral region [56], making quantitative comparison across instruments possible.

Figure 11 shows the comparison of the 3 AOD products. For several sites, we compute the mean AOD and its standard deviation with AERONET, week by week for the six years (Figure 11a) and synchronized in time ( $\pm 15 \mathrm{~min}$ ) with Deep Blue acquisition (Figure 11b). The results clearly show that NASCube is not accurate over Tamanrasset due to the difficulties to get a stable background reference (REF_PTB) in this region.

Figure 12 compares the retrieval AOD values for all areas and at coincident times. Deep Blue shows smaller standard deviations than NASCube, but Deep Blue completely discards AOD values larger than 2.0, in a range where NASCube and AERONET AOD orders of magnitude match fairly well. Note that NASCube tends to overestimate small AOD values below 0.3. This is certainly related to a lack of sensitivity of REF_PTB values. However, this deficiency does not hamper accurate sandstorm detections.

Figure 13 compares in more details the three AOD products by displaying the time-evolution of the weekly-integrated AOD values for three areas. A Bezier smoothing function is applied to eliminate the short time noise. Figure 13a,b illustrates two cases for which all three AOD products yield very similar AOD time profiles. Over Tamanrasset (Figure 13c), DEEPLUE profiles matches that of AERONET, while NASCube AOD values are overestimated. We suspect that this discrepancy might be attributed to difficulties in building the thermal reference over this mountainous area. On the contrary, over Sede-Boker (Figure 13d), NASCube is in line with AERONET, while Deep Blue AOD values are overestimated. 


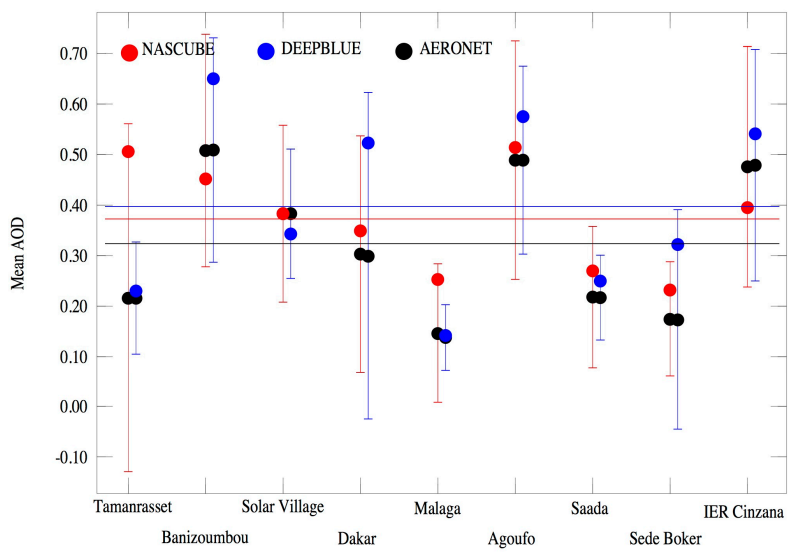

(a)

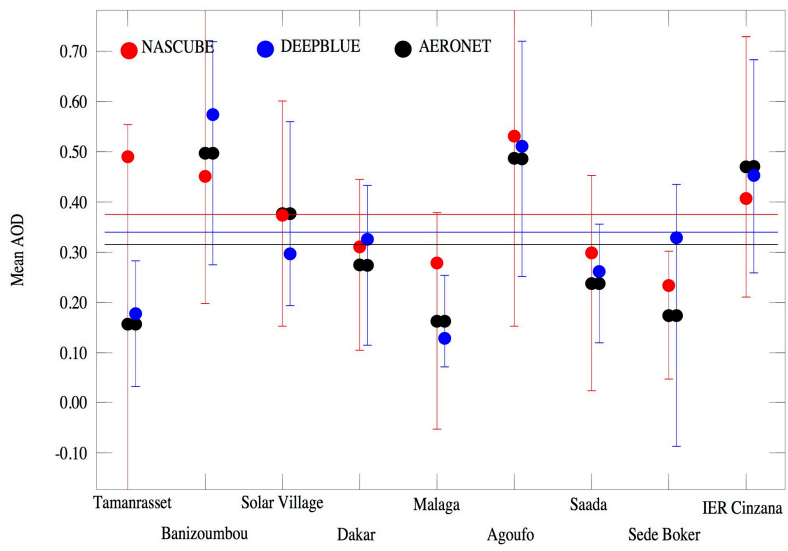

(b)

Figure 11. The AOD mean values and standard deviations with respect to AERONET for the NASCube (red) and Deep Blue (blue) at nine different locations from 2007-2012: (a) taking into account all measurements acquired by each instrument with a week integration time; and (b) the three instruments are synchronized to the Deep Blue acquisition time $\pm 10 \mathrm{~min}$.

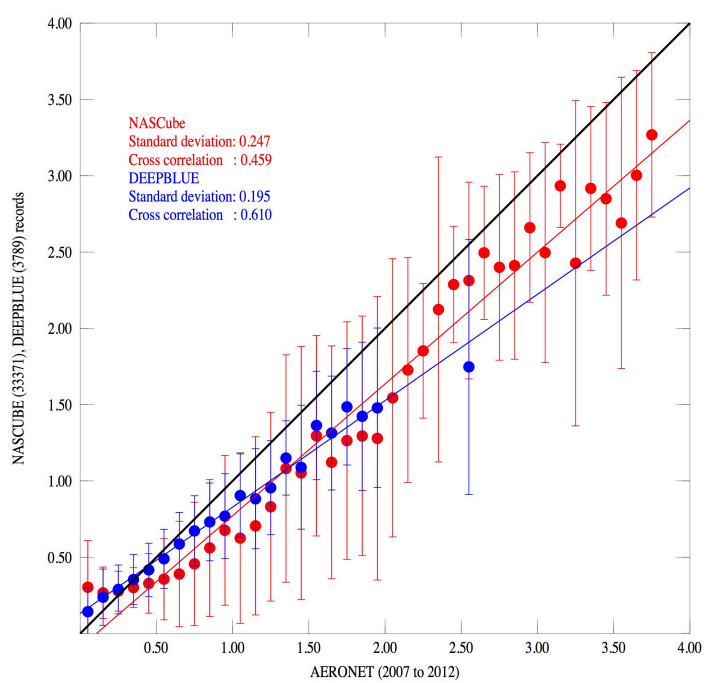

Figure 12. Comparison of Deep Blue $0.550 \mu \mathrm{m}$ (blue), NASCube $0.550 \mu \mathrm{m}$ (red) AOD retrievals to AERONET $0.440 \mu \mathrm{m}$ during 2007-2012. The dots represent the mean values and the error bars the standard deviations computed for AERONET AOD values split in classes of 0.1. 


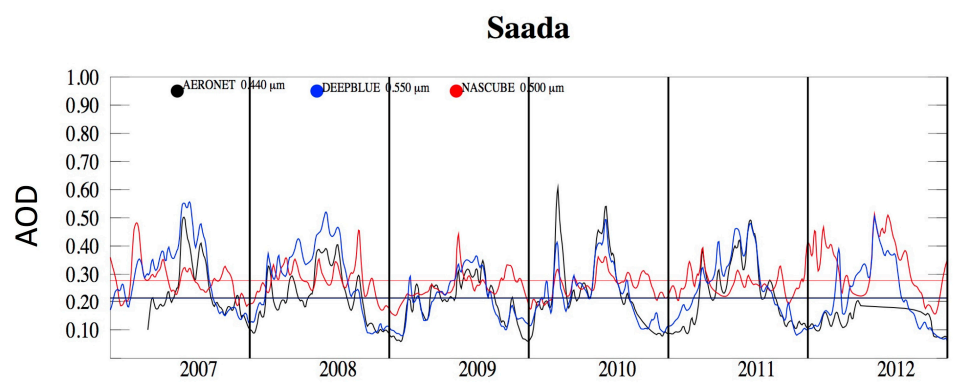

(a)

Solar-Village

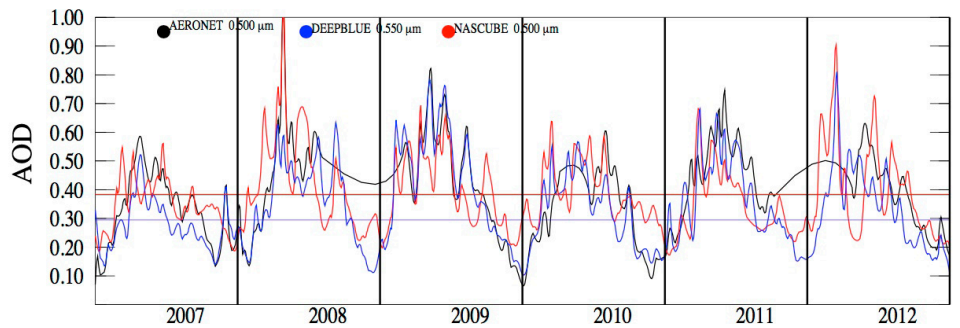

(b)

Tamanrasset

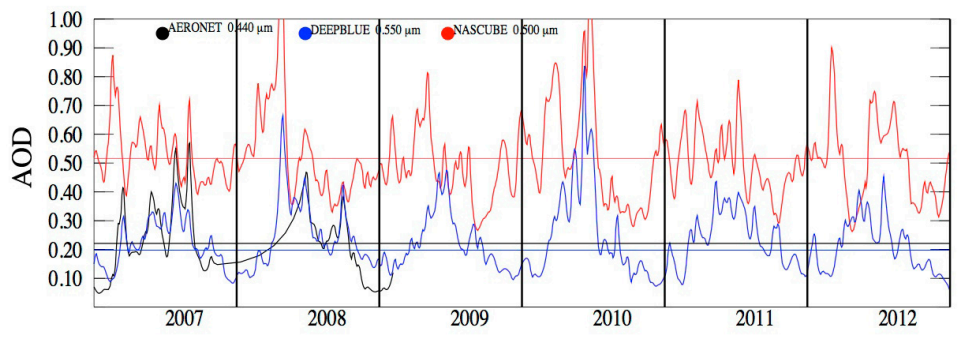

(c)

Sede-Boker

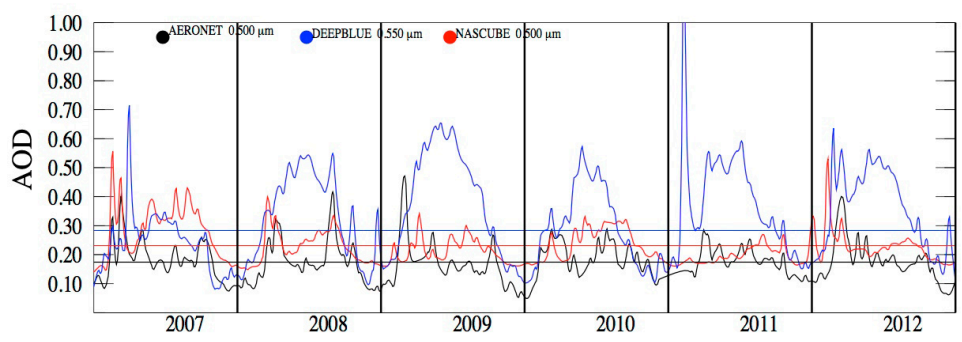

(d)

Figure 13. Time-evolutions of the AOD mean values at about $0.5 \mu \mathrm{m}$ averaged over a week for the three instruments during 2007-2012 (AERONET in black, Deep Blue in blue, and NASCube in red). Four specific AERONET sites have been selected: (a) Saasa; (b) Solar Village; (c) Tamanrasset; (d) Sede-Boker. A Bezier function is applied to eliminate short time variations.

In conclusion, we may infer that Deep Blue and NASCube products are complementary; NASCube may provide results for high AOD values, whereas Deep Blue has difficulties in particular over land areas, resulting in discontinuities between land and ocean AOD values, as revealed by several snapshots of Figure 14. Indeed, for matching time slots, the magnitude of the large Deep Blue AOD values over the ocean goes along with the NASCube AOD values retrieved over land, while there are severe ocean/land discrepancies in the Deep Blue AOD values. 

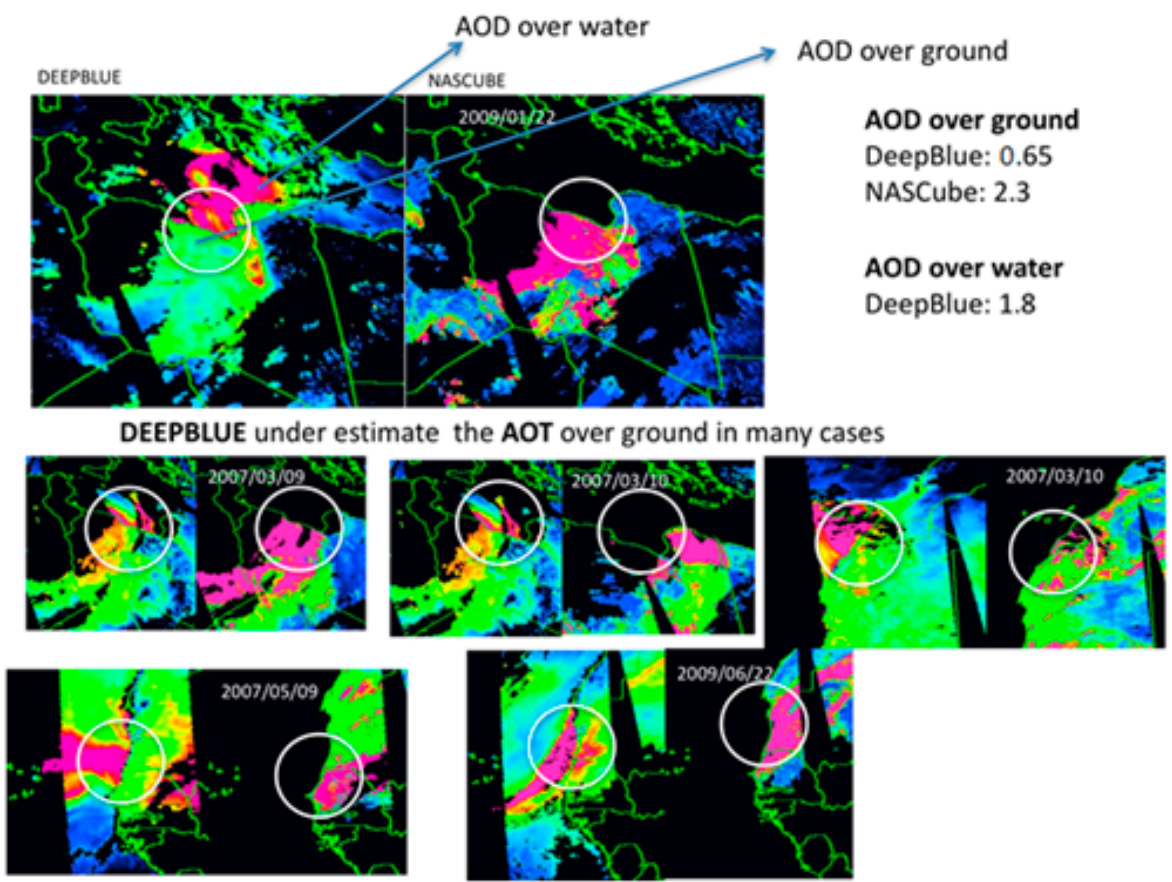

Figure 14. Overviews of Deep Blue (AQUA) (left inset) and NASCube (right inset) AOD values. NASCube only predicts AOD values over land. The various snapshots illustrate that Deep Blue AOD values are not continuous across land and ocean. On the other hand, the ocean Deep Blue results are close to the NASCube land ones.

\subsection{Validation of AOD Retrievals in Nighttime}

Our AOD product is now validated in nighttime. Figure 15 illustrates that there is no significant discontinuity in the structures and in the AOD values across the day/night boundaries for the three different transects.

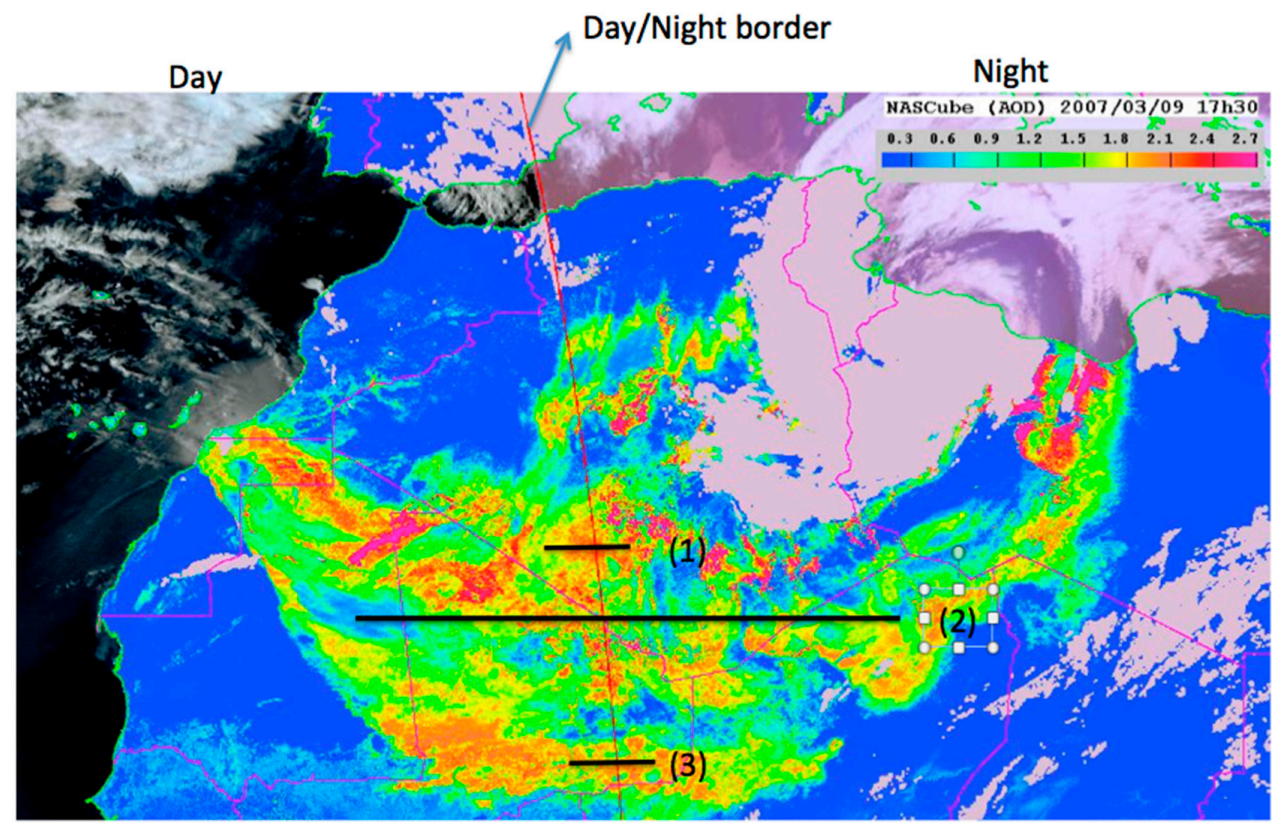

(a)

Figure 15. Cont. 
Transects

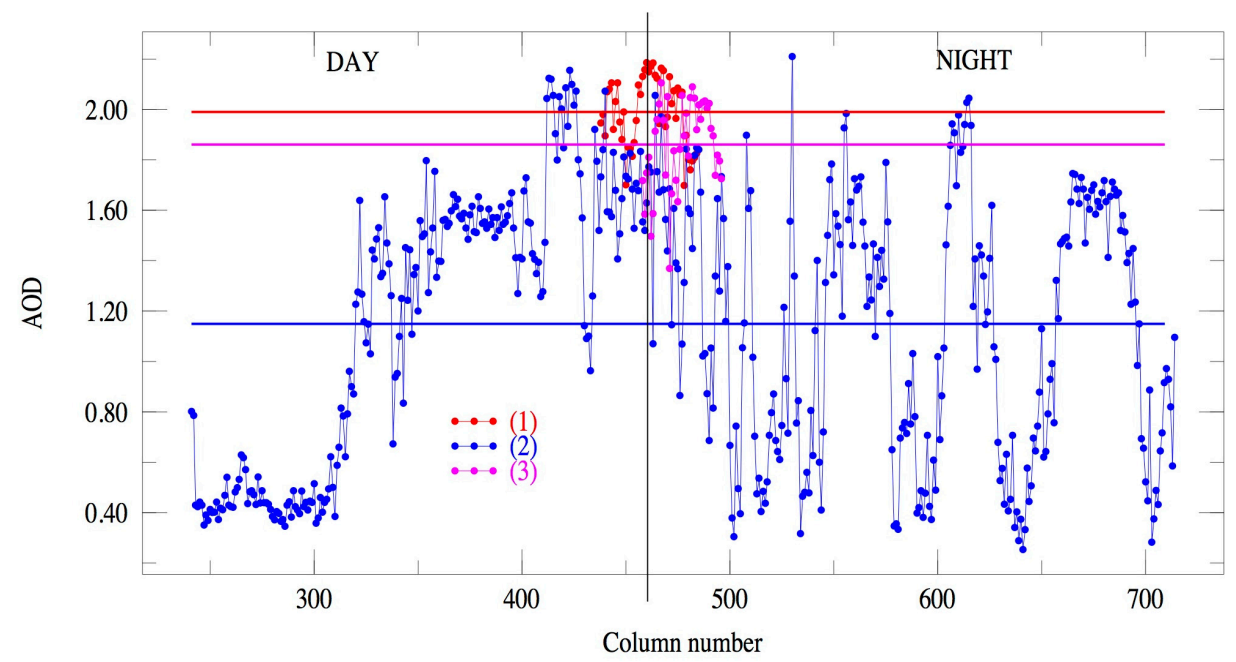

(b)

Figure 15. (a) Overview of day/night AOD retrievals on 9 March 2007; and (b) AOD profiles over three transects labeled (1), (2) and (3) across the day/night boundary; the horizontal lines correspond to the average values across the transect.

\section{Conclusions, Perspectives and the NASCube Website}

NASCube is the first attempt to provide to the scientific community an operational platform to detect sandstorms using SEVIRI measurements, with the ability of being easily tuned to the user needs and/or to implement several versions of the algorithm devoted to sandstorm detection. Figure 2 summarizes the NASCube system and the web service through a flowchart. The system has been running on a MAC Power G4 machine type for about 10 years with minimal human maintenance. The algorithm is only able to detect sandstorms over land so far; detection over water will be proposed at a later stage. The current detection algorithm has difficulties to retrieve AOD values below 0.3 and over bright areas such as the Bodele desert where the signal at the source level is so intense that it is beyond the algorithm detection. We have identified some sites where the AOD values are overestimated, such as Tamanrasset, as discussed in Section 3, and the reasons for this discrepancy are presently unclear. The availability of a 10-year database opens the way to extensions along the following lines: (1) sandstorm source detection; (2) tracking of sandstorm trajectories; (3) prediction of sandstorm trajectories at short time; (4) validating the nighttime AOD retrieval using numerous lunar photometer measurements; (5) improving sandstorm detections in mountainous areas by fine tuning the REF_PTBrgb reference, which will also help predicting small AOD values (below 0.3); and (6) building of a quantitative AOD retrieval over oceans.

The NASCube database has already been beneficial to several experiments such as the AMMA campaign of 2006, the FENNEC campaigns in 2011/2012 and in the ChArMEx campaign of 2012/2015.

A significant effort was devoted to the creation of a website [57] able to display the whole database results since 2006. The website can be regarded as a "blackboard" platform where we can implement new applications following our day-to-day needs or external user recommendations. The user is able to select and display any color composite over the seven years to near real time and download videos with the sandstorm inlays. Color code levels ranging from white to deep orange indicate the level of sandstorms in the calendars and daily sliders. The platform also provides a useful external interface to download the composite results using command lines either with wget or curl processes [58]. Statistics of the web access to the NASCube page [59] demonstrate that the older AMMA website was intensively used during 2007-2012 by French laboratories, while the currently running NASCube platform is hopefully interesting to English institutions as well. 
Acknowledgments: The authors wish to thank J. Pelon for is support to start the project in 2006 (AMMA), C. Flamant for is unconditional support in 2011 (FENEC) and C. Deroo for her invaluable technical advice and for the web site implementation. We wish to thank Eumetsat and Eumetcast for providing access to the MSG-SEVIRI instrument measurements. We thank V. E. Cachorro Revilla, E. Cuevas-Agullo, P. Goloub, B. N. Holben, A. Karnieli, B. Mougenot, J. L. Rajot, and D. Tanré, and their staff for establishing and maintaining the AERONET sites used in this investigation.

Author Contributions: Louis Gonzalez conceived the project, created and implemented the algorithms. Xavier Briottet contributed to the validation of the results. All authors contributed to the edition of the manuscript.

Conflicts of Interest: The authors declare no conflict of interest.

\section{References}

1. Climate Change 2013: The Physical Science Basis. In Working Group I Contribution to the Fifth Assessment Report of the Intergovernmental Panel on Climate Change (IPCC), Final Draft Underlying Scientific-Technical Assessment; Cambridge University Press: Cambridge, UK; New York, NY, USA, 2013.

2. Miller, R.L.; Tegen, I. Climate response to soil dust aerosols. J. Clim. 1998, 11, 3247-3267. [CrossRef]

3. Levin, Z.; Ganor, E.; Gladstein, V. The effects of desert particles coated with sulfate on rain formation in the eastern Mediterranean. J. Appl. Meteorol. 1996, 35, 1511-1523. [CrossRef]

4. McFiggans, G.; Artaxo, P.; Baltensperger, U.; Coe, H.; Facchini, M.; Feingold, G.; Fuzzi, S.; Gysel, M.; Laaksonen, A.; Lohmann, U. The effect of physical and chemical aerosol properties on warm cloud droplet activation. Atmos. Chem. Phys. 2006, 6, 2593-2649. [CrossRef]

5. Mahowald, N.M.; Kiehl, L.M. Mineral aerosol and cloud interactions. Geophys. Res. Lett. 2003, 30, 1475. [CrossRef]

6. Lee, S.S.; Penner, J.E. Aerosol effects on ice clouds: Can the traditional concept of aerosol indirect effects be applied to aerosol-cloud interactions in cirrus clouds? Atmos. Chem. Phys. 2010, 10, 10345-10358. [CrossRef]

7. Cuesta, J.; Marsham, J.H.; Parker, D.J.; Flamant, C. Dynamical mechanisms controlling the vertical redistribution of dust and the thermodynamic structure of the west Saharan atmospheric boundary layer during summer. Atmos. Sci. Lett. 2009, 10, 34-42. [CrossRef]

8. Washington, R.; Todd, M.C.; Engelstaedter, S.; Mbainayel, S.; Mitchell, F. Dust and the low-level circulation over the Bodélé depression, Chad: Observations from BoDEx 2005. J. Geophys. Res. 2006, 111, d03201. [CrossRef]

9. Slingo, A.; Ackerman, T.P.; Allan, R.P.; Kassianov, E.I.; McFarlane, S.A.; Robinson, G.J.; Barnard, J.C.; Miller, M.A.; Harries, J.E.; Russell, J.E.; et al. Observations of the impact of a major Saharan dust storm on the atmospheric radiation balance. Geophys. Res. Lett. 2006, 33, 124817. [CrossRef]

10. NASA Website. NASA Satellite Reveals How Much Saharan Dust Feeds Amazon's Plants. Available online: https:/ / www.nasa.gov / content/goddard/nasa-satellite-reveals-how-much-Saharan-dust-feedsamazon-s-plants (accessed on 22 February 2015).

11. Herrmann, L.; Jahn, R.; Maurer, T. Mineral dust around the Sahara-From source to sink. A review with emphasis on contributions of the German soil science community in the last twenty years. J. Plant Nutr. Soil Sci. 2010, 173, 811-821. [CrossRef]

12. Sokolik, I.N.; Toon, O.B. Incorporation of mineralogical composition into models of the radiative properties of mineral aerosol from UV to IR wavelengths. J. Geophys. Res. 1999, 104, 9423-9444. [CrossRef]

13. Alfaro, S.C.; Lafon, S.; Rajot, J.L.; Formenti, P.; Gaudichet, A.; Maillé, M. Iron oxides and light absorption by pure desert dust: An experimental study. J. Geophys. Res. 2004, 109, d08208. [CrossRef]

14. Falkowski, P.G.; Barber, R.T.; Smetacek, V. Biogeochemical controls and feedbacks on ocean primary production. Science 1998, 281, 200-206. [CrossRef] [PubMed]

15. Jickells, T.D.; An, Z.S.; Andersen, K.K.; Baker, A.R.; Bergametti, G.; Brooks, N.; Cao, J.J.; Boyd, P.W.; Duce, R.A.; Hunter, K.A.; et al. Global iron connections between desert dust, ocean biogeochemistry, and climate. Science 2005, 308, 67-71. [CrossRef] [PubMed]

16. Mahowald, N.M.; Baker, A.R.; Bergametti, G.; Brooks, N.; Duce, R.A.; Jickells, T.D.; Kubilay, N.; Prospero, J.M.; Tegen, I. Atmospheric global dust cycle and iron inputs to the ocean. Glob. Biogeochem. Cycles 2005, 19, gB4025. [CrossRef]

17. Koren, I.; Kaufman, Y.J.; Washington, R.; Todd, M.C.; Rudich, Y.; Martins, J.V.; Rosenfeld, D. The bodélé depression: A single spot in the Sahara that provides most of the mineral dust to the amazon forest. Environ. Res. Lett. 2006, 1, 014005. [CrossRef]

18. Bristow, C.S.; Hudson-Edwards, K.A.; Chappell, A. Fertilizing the amazon and equatorial Atlantic with West African dust. Geophys. Res. Lett. 2010, 37, 114807. [CrossRef] 
19. Escudero, M.; Querol, X.; Pey, J.; Alastuey, A.; Pérez, N.; Ferreira, F.; Alonso, S.; Rodríguez, S.; Cuevas, E. A methodology for the quantification of the net African dust load in air quality monitoring networks. Atmos. Environ. 2007, 41, 5516-5524. [CrossRef]

20. Gobbi, G.; Barnaba, F.; Ammannato, L. Estimating the impact of Saharan dust on the year 2001 pm10 record of Rome, Italy. Atmos. Environ. 2007, 41, 261-275. [CrossRef]

21. AERONET Website. Available online: https:/ / aeronet.gsfc.nasa.gov/ (accessed on 26 August 2017).

22. Prospero, J.M.; Ginoux, P.; Torres, O.; Nicholson, S.E.; Gill, T.E. Environmental characterization of global sources of atmospheric soil dust identified with the nimbus 7 total ozone mapping spectrometer (toms) absorbing aerosol product. Rev. Geophys. 2002, 40, 2-1-2-31, 1002. [CrossRef]

23. Washington, R.; Todd, M.; Middleton, N.J.; Goudie, A.S. Dust-storm source areas determined by the Total Ozone Monitoring Spectrometer and surface observations. Ann. Assoc. Am. Geogr. 2003, 93, 297-313. [CrossRef]

24. Schepanski, K.; Tegen, I.; Laurent, B.; Heinold, B.; Macke, A. A new Saharan dust source activation frequency map derived from MSG-SEVIRI IR-channels. Geophys. Res. Lett. 2007, 34, 118803. [CrossRef]

25. Ginoux, P.; Prospero, J.M.; Gill, T.E.; Hsu, N.C.; Zhao, M. Global-scale attribution of anthropogenic and natural dust sources and their emission rates based on MODIS deep blue aerosol products. Rev. Geophys. 2012, 50, rG3005. [CrossRef]

26. Knippertz, P.; Todd, M.C. The central west Saharan dust hot spot and its relation to African easterly waves and extratropical disturbances. J. Geophys. Res. 2010, 115, d12117. [CrossRef]

27. Hsu, N.C.; Tsay, S.-C.; King, M.D.; Herman, J.R. Aerosol properties over bright-reflecting source regions. IEEE Trans. Geosci. Remote Sens. 2004, 42, 557-569. [CrossRef]

28. Deep Blue NASA Website. Available online: https:/ / deepblue.gsfc.nasa.gov/ (accessed on 26 August 2017).

29. Schepanski, K.; Tegen, I.; Todd, M.C.; Heinold, B.; Bönisch, G.; Laurent, B.; Macke, A. Meteorological processes forcing Saharan dust emission inferred from MSG-SEVIRI observations of subdaily dust source activation and numerical models. J. Geophys. Res. 2009, 114, d10201. [CrossRef]

30. Ashpole, I.; Washington, R. An automated dust detection using SEVIRI: A multiyear climatology of summertime dustiness in the central and Western Sahara. J. Geophys. Res. 2012, 117, d08202. [CrossRef]

31. Legrand, M.; Plana-Fattori, A.; N'doumé, C. Satellite detection of dust using the ir imagery of Meteosat: 1. Infrared difference dust index. J. Geophys. Res. 2001, 106, 18251-18274. [CrossRef]

32. Klüser, L.; Schepanski, K. Remote sensing of mineral dust over land with MSG infrared channels: A new Bitemporal Mineral Dust Index. Remote Sens. Environ. 2009, 113, 1853-1867. [CrossRef]

33. Sannazzaro, F.; Filizzola, C.; Marchese, F.; Corrado, R.; Mazzeo, G.; Paciello, R.; Pergola, N.; Tramutoli, V. Identification of dust outbreaks on infrared MSG-SEVIRI data by using a Robust Satellite Technique (RST). Acta Astronaut. 2014, 93, 64-70. [CrossRef]

34. Murray, J.E.; Brindley, H.E.; Bryant, R.G.; Russell, J.E.; Jenkins, K.F.; Washington, R. Enhancing weak transient signals in SEVIRI false color imagery: Application to dust source detection in southern Africa. J. Geophys. Res. Atmos. 2016, 121, 10199-10219. [CrossRef]

35. Marchese, F.; Sannazzaro, F.; Falconieri, A.; Filizzola, C.; Pergola, N.; Tramutoli, V. An Enhanced Satellite-Based Algorithm for Detecting and Tracking Dust Outbreaks by Means of SEVIRI Data. Remote Sens. 2017, 9, 537. [CrossRef]

36. Brindley, H.E.; Ignatov, A. Retrieval of mineral aerosol optical depth and size information from Meteosat Second Generation SEVIRI solar reflectance bands. Remote Sens. Environ. 2006, 102, 344-363. [CrossRef]

37. Romano, F.; Ricciardelli, E.; Cimini, D.; Di Paola, F.; Viggiano, M. Dust detection and optical depth retrival using MSG-SEVIRI data. Atmosphere 2013, 4, 35-47. [CrossRef]

38. African Monsoon Multidisciplinary Analysis (AMMA) Experience Website. Available online: http://www. amma-international.org/ (accessed on 26 August 2017).

39. Flamant, C.; Chaboureau, J.-P.; Parker, D.J.; Taylor, C.M.; Cammas, J.-P.; Bock, O.; Timouk, F.; Pelon, J. Airborne observations of the impact of a convective system on the planetary boundary layer thermodynamics and aerosol distribution in the inter-tropical discontinuity region of the West African Monsoon. Q. J. R. Meteorol. Soc. 2007, 133, 1175-1189. [CrossRef]

40. DeSouza-Machado, S.G.; Strow, L.L.; Imbiriba, B.; McCann, K.; Hoff, R.M.; Hannon, S.E.; Martins, J.V.; Tanré, D.; Deuzé, J.L.; et al. Infrared retrievals of dust using airs: Comparisons of optical depths and heights derived for a North African dust storm to other collocated EOS A-Train and surface observations. J. Geophys. Res. 2010, 115, d15201. [CrossRef] 
41. Holben, B.; Eck, T.; Slutsker, I.; Tanré, D.; Buis, J.; Setzer, A.; Vermote, E.; Reagan, J.; Kaufman, Y.; Nakajima, T.; et al. AERONET-A federated instrument network and data archive for aerosol characterization. Remote Sens. Environ. 1998, 66, 1-16. [CrossRef]

42. Schmetz, J.; Govaerts, Y.; Konig, M.; Lutz, H.J.; Ratier, A.; Tjemkes, S. A Short Introduction to METEOSAT Second Generation (MSG); CIRA, Colorado State Univ.: Fort Collins, CO, USA, 2005.

43. Vermote, E.F.; Kotchenova, S.Y.; Tanré, D.; Deuzé, J.L.; Herman, M.; Roger, J.-C.; Morcrette, J.J. 6SV Code. Available online: http:/ / 6s.ltdri.org/2015 (accessed on 26 August 2017).

44. Vermote, E.F.; Tanré, D.; Deuzé, J.L.; Herman, M.; Morcette, J.J. Second simulation of the satellite signal in the solar spectrum, 6s: An overview. IEEE Trans. Geosci. Remote Sens. 1997, 35, 675-686. [CrossRef]

45. Shettle, E.P.; Kneizys, F.X.; Gallery, W.O. Suggested modification to the total volume molecular scattering coefficient in LOWTRAN: Comment. Appl. Opt. 1980, 19, 2873-2874. [CrossRef]

46. Vermote, E.; Tanré, D. Analytical expressions for radiative properties of planar rayleigh scattering media, including polarization contributions. J. Quant. Spec-Trosc. Radiat. Transf. 1992, 47, 305-314. [CrossRef]

47. Chandrasekhar, S. Radiative Transfer; Dover Publications, Inc.: New York, NY, USA, 2013.

48. Joseph, J.H.; Wiscombe, W.J.; Weinman, J.A. The Delta-Eddington approximation for radiative flux transfer. J. Atmos. Sci. 1976, 33, 2452-2459. [CrossRef]

49. Lenoble, J.; Herman, M.; Deuzé, J.; Lafrance, B.; Santer, R.; Tanré, D. A successive order of scattering code for solving the vector equation of transfer in the earth's atmosphere with aerosols. J. Quant. Spectrosc. Radiat. Transf. 2007, 107, 479-507. [CrossRef]

50. Zell, A.; Mache, N.; Huebner, R.; Mamier, G.; Vogt, M.; Schmalzl, M.; Herrmann, K.U. SNNS (Stuttgart Neural Network Simulator). In Neural Network Simulation Environments; Springer: Boston, MA, USA, 1994; pp. 165-186.

51. Prata, A.J.; Grant, I.F. Retrieval of microphysical and morphological properties of volcanic ash plumes from satellite data: Application of Mountain Ruapehu, New Zealand. Q. J. R. Meteorol. Soc. 2000, 122, 1-999. [CrossRef]

52. Lensky, I.M.; Rosenfeld, D. Clouds-Aerosols-Precipitation Satellite Analysis Tool (CAPSAT). Atmos. Chem. Phys. 2008, 8, 6739-6753. [CrossRef]

53. Ackerman, S.A. Remote sensing aerosols using satellite infrared observations. J. Geophys. Res. 1997, 102, 17069-17079. [CrossRef]

54. Eumetsat. Cloud Mask Factsheet; EUM/OPS/DOC/09/5164; Eumetsat: Darmstadt, Germany, 2010.

55. Taravat, A.; Frate, F.D.; Cornaro, C.; Vergari, S. Neural networks and support vector machine algorithms for automatic cloud classification of whole-sky ground-based images. IEEE Geosci. Remote Sens. Lett. 2015, 12, 666-670. [CrossRef]

56. Sayer, A.M.; Munchak, L.A.; Hsu, N.C.; Levy, R.C.; Bettenhausen, C.; Jeong, M.-J. MODIS Collection 6 aerosol products: Comparison between Aqua's e-Deep Blue, Dark Target, and "merged" data sets, and usage recommendations. J. Geophys. Res. Atmos. 2014, 119, 13965-13989. [CrossRef]

57. North African Sand Storm Survey NASCube Website. Available online: http://nascube.univ-lille1.fr/ (accessed on 26 August 2017).

58. NASCube Acquisition Commands. Available online: http://nascube.univ-lille1.fr/Abonnt/getimage.html/ (accessed on 26 August 2017).

59. NASCube Statistics. Available online: http://newtec.univ-lille1.fr/Movies/WEBSTATS/WS2017.html (accessed on 26 August 2017).

(C) 2017 by the authors. Licensee MDPI, Basel, Switzerland. This article is an open access article distributed under the terms and conditions of the Creative Commons Attribution (CC BY) license (http://creativecommons.org/licenses/by/4.0/). 